\title{
Efeito antitumoral do chá verde no carcinoma de células escamosas oral: Revisão
}

\section{integrativa}

\author{
Antitumoral effect of green tea on oral squamous cell carcinoma: Integrative review \\ Efecto antitumoral del té verde en el carcinoma de células escamosas oral: Revisión integradora
}

Recebido: 10/06/2021 | Revisado: 18/06/2021 | Aceito: 19/06/2021 | Publicado: 04/07/2021

William José e Silva Filho

ORCID: https://orcid.org/0000-0002-2117-3352 Universidade Federal de Sergipe, Brasil

E-mail: williamjsfilho10@gmail.com

Divyashree Singh

ORCID: https://orcid.org/0000-0003-0077-6039 Universidade Federal de Sergipe, Brasil E-mail: divyashreesingh01@gmail.com

Shalini Singh

ORCID: https://orcid.org/0000-0002-8369-5666 Universidade Federal de Sergipe, Brasil E-mail: shalinisingh@outlook.com.br

Rosilene Calazans Soares

ORCID: https://orcid.org/0000-0002-8392-9653 Universidade Federal de Sergipe, Brasil

E-mail: rosilene@academico.ufs.br

Débora dos Santos Tavares

ORCID: https://orcid.org/0000-0001-5452-0771 Universidade Federal de Sergipe, Brasil

E-mail: tavaresdebora@gmail.com

\begin{abstract}
Resumo
Objetivo: Avaliar o efeito antitumoral do chá verde e seus compostos naturais no carcinoma de células escamosas oral (CCEO). Metodologia: Trata se de uma revisão integrativa da literatura a partir da questão norteadora "O chá verde tem efeito antitumoral no desenvolvimento do CCEO?". A busca foi realizada com os descritores "Camellia sinensis", "Green tea"; "Oral cancer"; "squamous cell carcinoma"; "animals" e "anticarcinogenic agents" nas bases de dados PubMed, Science Direct, Scielo e Google Acadêmico. Os critérios de inclusão foram artigos científicos sobre o efeito do chá verde, na forma de extrato ou compostos isolados, no CCEO, estudos in vivo, em qualquer idioma. Resultados: Obteve-se um total de 1.245 artigos, dentre os quais 11 foram selecionados. A maioria dos estudos $(90,9 \%)$ foi realizada por países orientais. A epigalocatequina-galato, hamsters e DMBA foram os compostos, modelo animal e carcinógeno mais usados, respectivamente. Observou-se diversos mecanismos de ação (estresse oxidativo, apoptose, inibição da proliferação e diferenciação celular) e efeitos moleculares (alteração na expressão de glicoconjugados, proteínas precursoras amilóides, metaloproteinases e na formação de invadopódios) do chá verde no CCEO. Considerações finais: O chá verde possui efeito antitumoral no carcinoma de células escamosas oral, exercendo ação tanto quimiopreventiva quanto terapêutica, por diferentes vias. Por ser um produto natural, biocompatível, seguro e de fácil acesso/baixo custo seu uso deve ser explorado de forma a contribuir para o tratamento/prevenção do CCEO, o tipo mais frequente de câncer oral.
\end{abstract}

Palavras-chave: Chá verde; Camellia sinensis; Câncer oral; Carcinoma de células escamosas; Animais.

\begin{abstract}
Objective: To evaluate the antitumor effect of green tea and its natural compounds on oral squamous cell carcinoma (OSCC). Methodology: This is an integrative literature review based on the guiding question "Does green tea have an anti-tumor effect on the development of OSCC?". The search was carried out with the descriptors "Camellia sinensis", "Green tea"; "Oral cancer"; "Squamous cell carcinoma"; "Animals" and "anticarcinogenic agents" in the PubMed, Science Direct, Scielo and Google Scholar databases. The inclusion criteria were scientific articles on the effect of green tea, in the form of extract or isolated compounds, in the OSCC, in vivo studies, in any language. Results: A total of 1,245 articles were obtained, of which 11 were selected. Most studies (90.9\%) were carried out by eastern countries. Epigallocatechin gallate, hamsters and DMBA were the most used compounds, animal model and carcinogen, respectively. There were several mechanisms of action (oxidative stress, apoptosis, inhibition of cell proliferation and differentiation) and molecular effects (alteration in the expression of glycoconjugates, amyloid precursor proteins, metalloproteinases and the formation of invadopodia) in green tea. Final considerations: Green tea has an anti-tumor
\end{abstract}


effect on oral squamous cell carcinoma, exerting both chemopreventive and therapeutic action, by different routes. As it is a natural, biocompatible, safe and easily accessible/low cost product, its use should be explored in order to contribute to the treatment / prevention of OSCC, the most frequent type of oral cancer.

Keywords: Green tea; Camellia sinensis; Oral cancer; Squamous cell carcinoma; Animals.

\section{Resumen}

Objetivo: Evaluar el efecto antitumoral del té verde y sus compuestos naturales en el carcinoma oral de células escamosas (CCEO). Metodología: Se trata de una revisión integradora de la literatura basada en la pregunta orientadora “¿Tiene el té verde un efecto antitumoral en el desarrollo de CCEO?”. La búsqueda se realizó con los descriptores "Camellia sinensis", "Té verde"; "Cáncer oral"; "Carcinoma de células escamosas"; “Animales" y "agentes anticancerígenos" en las bases de datos PubMed, Science Direct, Scielo y Google Scholar. Los criterios de inclusión fueron artículos científicos sobre el efecto del té verde, en forma de extracto o compuestos aislados, en el CCEO, estudios in vivo, en cualquier idioma. Resultados: Se obtuvieron un total de 1.245 artículos, de los cuales se seleccionaron 11. La mayoría de los estudios $(90,9 \%)$ fueron realizados por países del este. Epigalocatequina-galato, hámsters y DMBA fueron los compuestos más utilizados, modelo animal y carcinógeno, respectivamente. Hubo varios mecanismos de acción (estrés oxidativo, apoptosis, inhibición de la proliferación y diferenciación celular) y efectos moleculares (alteración en la expresión de glicoconjugados, proteínas precursoras amiloides, metaloproteinasas y formación de invadopodios) en el té verde. Consideraciones finales: El té verde tiene un efecto antitumoral sobre el carcinoma de células escamosas oral, ejerciendo acción tanto quimiopreventiva como terapéutica, por diferentes vías. $\mathrm{Al}$ ser un producto natural, biocompatible, seguro y de fácil acceso/bajo costo, se debe explorar su uso para contribuir al tratamiento / prevención del CCEO, el tipo de cáncer oral más frecuente.

Palabras clave: té verde; Camellia sinensis; Cáncer oral; Carcinoma de células escamosas; Animales.

\section{Introdução}

O câncer de boca é considerado uma doença crônica de caráter multifatorial, onde os processos de controle da proliferação celular são afetados (Herrera-Serna, 2019). Os fatores de risco mais importantes que contribuem para o seu desenvolvimento são o consumo de álcool e o tabagismo, além do papiloma vírus humano, especialmente os subtipos 16 e 18 (Herrera-Serna, 2019; Chimenos-Küstner; Marques-Soares; Schemel-Suárez, 2019). Ainda, sabe-se que quanto menor o índice socioeconômico, maior desigualdade social e maior necessidade de orientação das políticas públicas de combate ao câncer de boca (Maciel, 2021). Nesse cenário, o câncer de boca caracteriza-se como um problema de Saúde Pública em que os indicadores epidemiológicos da doença, apesar dos avanços científicos, não melhoram ao longo do tempo. As dificuldades em se estabelecer políticas públicas direcionadas ao combate ao câncer, somado a fatores relacionados ao paciente e/ou ao profissional, juntos ou isolados, contribuem para a demora do seu diagnóstico e agravamento de suas consequências (Torres-Pereira et al, 2012).

De acordo com Instituto Nacional do Câncer (2020), estimam-se 15.190 novos casos de câncer de boca para o ano de 2020, sendo 11.180 em homens e 4.010 em mulheres. Esse tipo de câncer possui significativas taxas de morbimortalidade devido à recidiva loco-regional e metástases linfonodais. Sabe-se que o carcinoma de células escamosas oral (CCEO) representa mais de $90 \%$ dos casos de câncer na região da cabeça e pescoço (Tandon et al., 2017) e apesar dos avanços terapêuticos essas taxas não foram significativamente alteradas. Assim, o tratamento do câncer de boca ainda representa um desafio, sendo importante o desenvolvimento de novas técnicas e drogas voltadas para o tratamento antiproliferativo (Rivera, 2015).

Uma vez que o câncer está associado a uma alta morbidade e mortalidade no mundo, há uma necessidade urgente de determinar formas de manejo dessa doença, que atualmente incluem cirurgia, radioterapia, quimioterapia, terapia gênica e/ou terapia hormonal. Produtos naturais, especialmente os derivados de plantas, têm sido usados para ajudar a humanidade na manutenção da saúde desde os primórdios da Medicina. Hoje em dia, assim como na antiguidade, os compostos naturais ainda são fatores determinantes no desenvolvimento de medicamentos (Rady et al., 2018; Moghadamtousi et al., 2015; Peter; Bosze; Horvath, 2016).

O chá é uma das bebidas mais consumidas no mundo e seu potencial terapêutico é estudado há muito tempo. Existe uma grande diversidade de chás e formas de preparo. Os chás derivados da planta medicinal Camellia sinensis incluem o chá verde, preto e oolong, e seus hábitos de consumo variam culturalmente (Filippini et al., 2020). A Camellia sinensis contém 
polifenóis que são representantes do subgrupo catequinas e devido a sua biocompatibilidade e ação antioxidante, seu potencial de inibição da proliferação de células cancerosas vem sendo estudado a fim de validar seu uso como prevenção ou tratamento coadjuvante na terapia do câncer (Filippini et al., 2020; Liao et al., 2020).

Os principais polifenóis encontrados no chá verde são a epigalocatequina-3-galato (EGCG), epigalocatequina (EGC), epicatequina-3-galato (ECG) e epicatequina (EC). O consumo regular dos polifenóis tem sido associado a um risco reduzido de uma série de doenças crônicas, doenças cardiovasculares, neurodegenerativas e câncer (Chowdhury et al., 2016; Liao et al., 2020). Dentre os compostos do chá verde, destaca-se a epigalocatequina-3-galato (EGCG), caracterizada como um composto natural e devido a sua segurança e perfil de toxicologia, vem sendo considerada uma droga promissora para a prevenção e terapia do câncer (Maggioni et al., 2015). Diante disso, esta revisão integrativa visa avaliar criticamente o efeito antitumoral do chá verde e seus compostos naturais no carcinoma de células escamosas oral, em estudos pré-clínicos com animais.

\section{Metodologia}

As fases da revisão integrativa do estudo foram: definição do tema e desenho do trabalho, critérios para a seleção dos estudos, pesquisa e avaliação dos dados, interpretação dos resultados e redação da revisão. Para auxílio nessa etapa, foram utilizadas fichas de coleta de dados constituídas de ano da publicação, tipo de estudo e tema principal como objeto do estudo. O estudo foi guiado pela seguinte pergunta norteadora: "O chá verde tem efeito antitumoral no desenvolvimento do carcinoma de células escamosas oral?". A busca foi realizada com os descritores baseados no Medical Subject Headings (MeSH) e nos Descritores em Ciências da Saúde (DeCS), com o auxílio dos operadores boleanos (and/or) nas bases de dados: National Library of Medicine (PubMed), Science Direct, Scientific Eletronic Library Online (SciELO) e Google Acadêmico, conforme Tabela 01.

A seleção dos artigos foi realizada entre os meses de fevereiro a abril de 2021 pelo avaliador 01. Quaisquer dúvidas foram resolvidas em reuniões consensuais com o avaliador 02 Após a busca, a revisão foi dividida em duas etapas: a primeira consistiu na seleção dos artigos com base nos títulos e resumos, de acordo com os critérios de elegibilidade e a segunda consistiu na aplicação desses critérios para inclusão definitiva dos artigos com base na leitura do texto completo. Uma busca manual nas referências dos artigos incluídos foi realizada para detecção de possíveis trabalhos elegíveis a serem incluídos.

Os critérios de inclusão estabelecidos foram artigos científicos, incluindo ensaios originais, disponíveis eletronicamente, sobre o efeito do chá verde, na forma de extrato ou compostos isolados, no carcinoma de células escamosas oral, estudos in vivo (animais), publicados em periódicos nacionais e internacionais em qualquer idioma. Os critérios de exclusão foram capítulos de livro, dissertações, tese, resumos, tumores comprovadamente resistentes a antineoplásicos comerciais, estudos in vitro, artigos com seres humanos e aqueles sem acesso ao texto completo. Artigos que abordam outros tipos de câncer associados e que estudam o chá verde associado a outras substâncias/compostos ou na forma de óleos essenciais também foram excluídos do estudo.

As informações dos artigos incluídos foram descritas na forma de tabelas com as seguintes informações: autor, ano e país de publicação, método de obtenção do chá, concentração/tipo de composto, modelo animal, dose/tempo de administração/grupos, resultados principais (histopatológicos e moleculares) e conclusão. Além disso, os estudos foram classificados de acordo com seu objetivo em terapêuticos ou preventivos. Considerou-se estudos terapêuticos aqueles que administraram o chá verde ou seus compostos após a indução do câncer nos animais e estudos preventivos aqueles nos quais o chá verde ou seus compostos foram administrados concomitantemente e/ou antes da indução do câncer. 
Tabela 1 - Termos de busca em cada base de dados.

\begin{tabular}{lll}
\hline Base de dados & \multicolumn{3}{c}{ Descritores } \\
\hline PubMed & ("Camellia sinensis" OR "Green Tea") AND \\
& ("Oral cancer" OR "squamous cell \\
& carcinoma") & \\
\hline Science Direct & ("Camellia sinensis" OR "Green Tea") AND \\
& ("Oral cancer" OR "squamous cell \\
& carcinoma") AND animals \\
\hline Scielo & ("Green tea" OR "Camellia sinensis" AND \\
& "Cancer") & \\
\hline Google Acadêmico & ("Camellia sinensis" OR "Green Tea") AND \\
& ("Oral cancer" OR "squamous cell \\
& carcinoma") AND ("anticarcinogenic \\
& agents") & \\
\hline
\end{tabular}

Fonte: Autores (2021).

\section{Resultados}

Por meio da busca realizada nas bases de dados PubMed, ScienceDirect, SciELO e Google Acadêmico obteve-se um total de 1.245 artigos, que depois da remoção das duplicatas, através do software Rayyan, totalizou 1.149 artigos. Após aplicação dos critérios de inclusão e exclusão, restaram 10 artigos e, finalmente, após busca manual da lista de referências, foi incluído mais um artigo, totalizando 11 artigos (Figura 1). 
Figura 1 - Fluxograma do processo de seleção dos estudos.

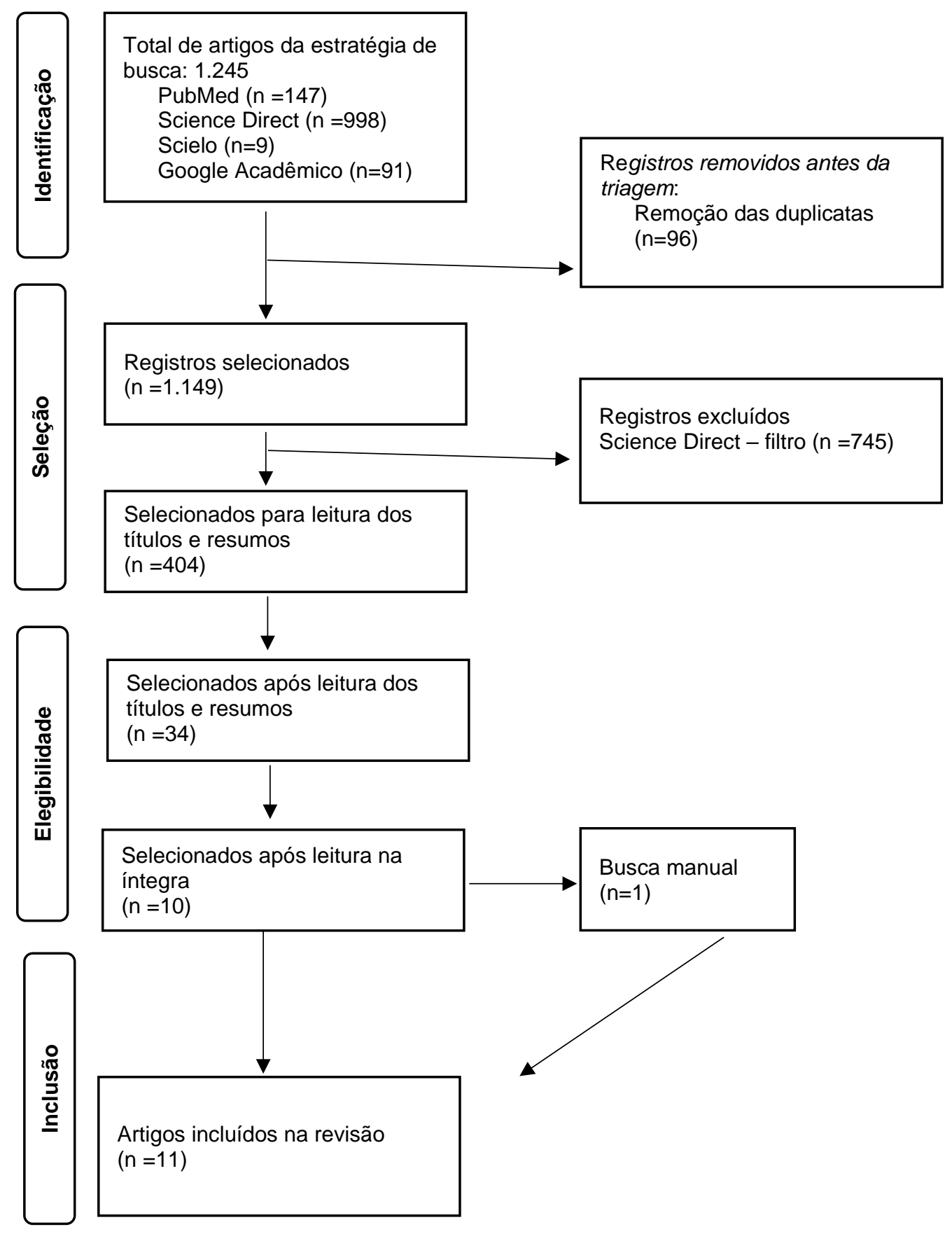

Fonte: Autores (2021). 
Tabela 2: Descrição detalhada dos estudos in vivo incluídos.

\begin{tabular}{|c|c|c|c|c|c|}
\hline $\begin{array}{c}\text { Autor (ano) } \\
\text { [País] }\end{array}$ & $\begin{array}{l}\text { Fonte de obtenção do } \\
\text { chá/composto }\end{array}$ & Animais/Carcinógeno & $\begin{array}{c}\text { Grupos (dose/tempo de } \\
\text { tratamento) / Efeito preventivo } \\
\text { ou terapêutico }\end{array}$ & Resultados principais & Conclusão \\
\hline $\begin{array}{l}\text { Li; Han; } \\
\text { Chen, (1999) } \\
\text { [China] }\end{array}$ & $\begin{array}{l}\text { Chá verde, pigmentos } \\
\text { do chá, e chá misto } \\
\text { elaborado pelo } \\
\text { Instituto de Ciência e } \\
\text { Pesquisa do Chá da } \\
\text { Academia Chinesa de } \\
\text { Ciências Agrícolas. } \\
\text { O extrato aquoso do } \\
\text { chá foi preparado } \\
\text { diariamenter da } \\
\text { seguinte forma: } 1,5 \mathrm{~g} \\
\text { de folhas frescas de } \\
\text { chá verde (Long Jin) } \\
\text { foram infundidos em } \\
100 \text { ml de água } \\
\text { fervente, deixados em } \\
\text { temperatura ambiente } \\
\text { por } 30 \text { minutos e, em } \\
\text { seguida, filtrados. } \\
\text { Pigmentos de chá } \\
\text { (produto oxidado de } \\
\text { polifenóis de chá } \\
\text { verde a } 40 \% \text { foram } \\
\text { dissolvidos em água } \\
\text { da torneira a uma } \\
\text { concentração de de } \\
0,1 \% \text { o chá } \\
\text { misturado foi } \\
\text { preparado a partir do } \\
\text { extrato aquoso de chá } \\
\text { verde liofilizado, } \\
\text { polifenóis do chá } \\
\text { (40\% de pureza) e }\end{array}$ & $\begin{array}{l}\text { Hamsters sírios dourados } \\
\text { machos }(60-90 \mathrm{~g}) \text {. } \\
\text { 7,12- dimetilbenz(A) } \\
\text { antraceno (DMBA) (Sigma } \\
\text { Chemical, St. Louis, MO) a } \\
0,5 \%(50 \mu \mathrm{l}) \text { em acetona foi } \\
\text { pincelado na bolsa jugal } \\
\text { direita dos animais } \\
\text { 3x/semana durante } 15 \\
\text { semanas, seguido de período } \\
\text { de observação de } 6,10 \text { e } 15 \\
\text { semanas. }\end{array}$ & $\begin{array}{l}\text { Grupo } 1 \text { (n=32): controle } \\
\text { positivo, animais submetidos a } \\
\text { indução de câncer com } \\
\text { DMBA. } \\
\text { Grupo } 2 \text { de chá verde (n=32): } \\
\text { animais submetidos a indução } \\
\text { de câncer, tratados com 1,5\% } \\
\text { de chá verde como única fonte } \\
\text { de água potável por duas } \\
\text { semanas antes da indução com } \\
\text { DMBA e até o final do } \\
\text { experimento. } \\
\text { Grupo } 3 \text { de pigmentos de chá } \\
\text { (n=32): animais submetidos a } \\
\text { indução de câncer, tratados } \\
\text { com 0,1\% de pigmentos de chá } \\
\text { como única fonte de água } \\
\text { potável por duas semanas } \\
\text { antes da indução com DMBA e } \\
\text { até o final do experimento. } \\
\text { Grupo } 4 \text { de chá misto (n=32): } \\
\text { animais submetidos a indução } \\
\text { de câncer, tratados com 0,5\% } \\
\text { de chá misturado como única } \\
\text { fonte de água potável por duas } \\
\text { semanas antes do início da } \\
\text { indução com DMBA e até o } \\
\text { final do experimento. } \\
\text { Grupo } 5 \text { (n=10): controle } \\
\text { negativo, aplicação de acetona } \\
\text { ao invés do DMBA, seguindo o } \\
\text { mesmo protocolo, sem } \\
\text { tratamento, eutanasiados na } \\
15^{a} \text { semana. }\end{array}$ & 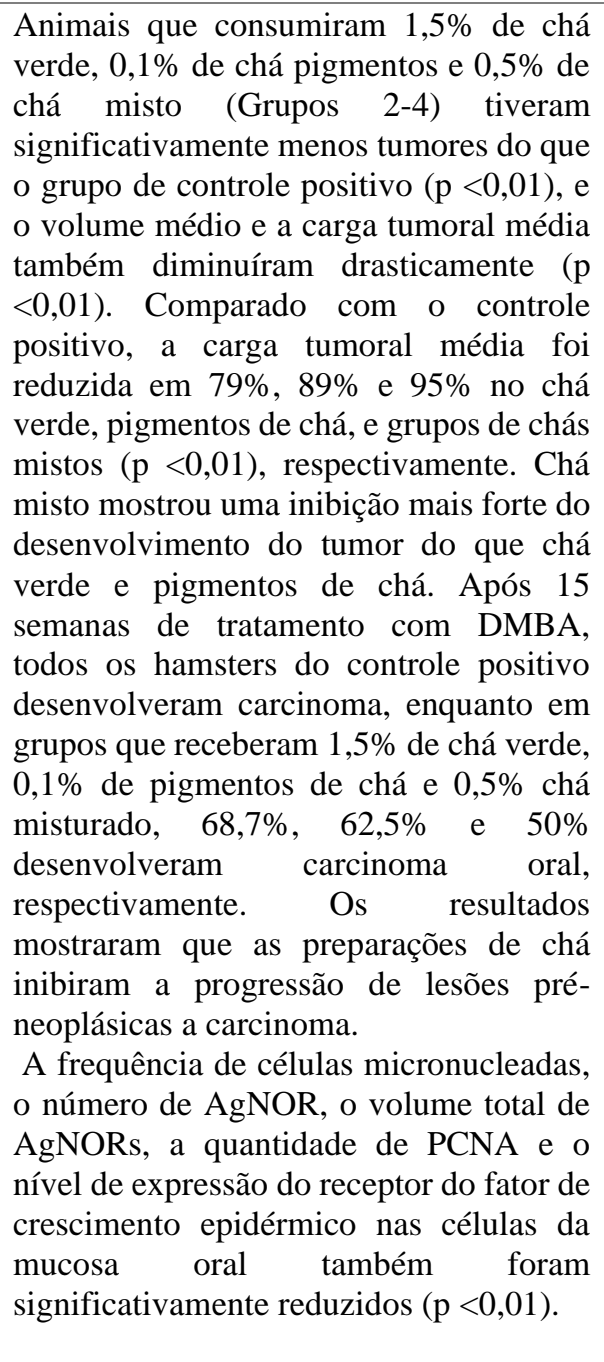 & $\begin{array}{l}\text { As preparações de chá } \\
\text { podem inibir efetivamente a } \\
\text { carcinogênese oral induzida } \\
\text { por DMBA em hamsters. A } \\
\text { proteção contra danos ao } \\
\text { DNA e a supressão da } \\
\text { proliferação celular podem } \\
\text { ser mecanismos importantes } \\
\text { dos efeitos } \\
\text { anticarcinogênicos das } \\
\text { preparações de chá. } \\
\text { O chá misturado mostrou } \\
\text { efeitos inibitórios mais fortes } \\
\text { do que qualquer ingrediente } \\
\text { do chá testado de forma } \\
\text { isolada nesse estudo. }\end{array}$ \\
\hline
\end{tabular}


pigmentos de chá na proporção

de $4: 1: 1$, e dissolvidos em água da torneira a uma concentração de $0,5 \%$
Os hamsters foram pesados a cada duas semanas, e o consumo diário de chá e água foi registrado. Oito, 8 e 16 hamsters nos Grupos 1-4 foram eutanasiados após 6, 10 e 15 semanas de tratamento com DMBA, respectivamente.

Avaliação do efeito preventivo.

\begin{tabular}{llll}
\hline Li et al., & Chá verde em pó & Golden hamsters sírios \\
(2002) [EUA] & contendo 15,1\% & machos (6 semanas com 60- \\
& epigalocatequina-3- & $80 \mathrm{~g})$. \\
& galato, $\quad 8,7 \%$ & \\
& epigalocatequina, 4,3 & $100 \mu \mathrm{l}$ DMBA (Sigma) a \\
& epicatequina-3- & $0,5 \%$, em óleo mineral, \\
& galato, \\
& epicatequina e 5,4\% & pincelado na bolsa jugal \\
& cafeína (Thomas J. & 6 semanas. \\
& Lipton Tea Company, \\
& Englewood Cliffs, \\
& NJ)
\end{tabular}

Dois dias após finalizada indução com DMBA:

Grupo teste $(n=28)$ : tratamento com chá verde $(6 \mathrm{mg} / \mathrm{mL})$ à vontade para beber por 18 semanas.

Grupo controle $\quad(n=28)$ : controle sem tratamento por 18 semanas, água de beber

Grupo controle $(\mathrm{n}=10): 8$ animais eutanasiados 2 dias após indução por DMBA, 2 foram observados por 18 semanas.

Avaliação do efeito terapêutico.

Srinivasan;
Sabitha;
Shyamaladev
i,(2004)
[Î́ndia]

Folhas frescas de chá Ratos albinos Wistar machos verde coletados do (10 semanas com 180-200g). distrito de Nilgris (Índia), submetidas a extração alcoólica, contendo cerca de $80 \%$ de polifenóis totais do chá verde (GTP).
Grupo I ( $\mathrm{n}=12)$ : controle, sem

indução de câncer.

Grupo II $(n=12)$ : animais 4-NQO (Sigma Chemical

Company/St. Louis, MO, câncer. $\begin{array}{lll}\text { EUA) a } 0,5 \% & \text { em } \\ \text { propilenoglicol foi pincelado }\end{array}$ $3 \mathrm{X} /$ semana durante 12 semanas, seguido de 10 semanas de observação para formação do câncer $\left(22^{\mathrm{a}}\right.$ semana) (polifenóis do chá verde) por roga, após $22^{\mathrm{a}}$ semana, recebeu $200 \mathrm{mg}$ de $\mathrm{GTP} / \mathrm{kg}$ 30 dias, via oral, animais sem indução de câncer.

Grupo IV $(n=12)$ : tratados, <0,001) enquanto os níveis de GSSG após $22^{\mathrm{a}}$ semana, recebeu 200 dienos conjugados e a atividade de GGT
Aplicação tópica de DMBA por 6 O chá verde inibiu a semanas produziu hiperplasia $(100 \%)$ e carcinogênese oral na fase displasia $(75 \%)$, e CCE em $77 \%$ dos pós-iniciação, possivelmente animais em 18 semanas. Chá verde associado à redução da o numero de tumores visíveis em proliferação celular e $35,1 \%$, volume do tumor em $41,6 \%$ e indução da apoptose. Seu uso úmero de CCE em 53,3\%. Houve como agente redução do número de lesões displásicas e quimiopreventivo pode ser umento significativo do grau de explorado em casos de alto poptose nas displasias e CCE. Ainda, risco de câncer oral, como houve redução da proliferação celular nas leucoplasias e eritroplasias displasias, hiperplasias e papilomas. em ex-fumantes. 
mg de GTP/kg (polifenóis do foram aumentados $(\mathrm{p}<0,001)$ em ratos chá verde) por 30 dias via oral, da $22^{\mathrm{a}}$ a $26^{\mathrm{a}}$ semana, animais submetidos a indução por DMBA.

Avaliação do efeito terapêutico. submetidos a indução de câncer (Grupo II), quando comparados com ratos controle (Grupo I). Em ratos induzidos para câncer oral, a suplementação de GTP por 30 dias aumentou os níveis de GSH (P $<0,05)$, PSH $(\mathrm{P}<0,01)$ e tióis totais e diminuiu o nível de GSSG, dienos conjugados e a atividade de GGT (Grupo IV).

Administração de GTP aumentou significativamente os níveis de GSH, PSH e tióis totais e reduziram significativamente os níveis de GSSG, dienos conjugados e a atividade de GGT quando comparados com ratos induzidos por câncer oral.

Chandra

(2005)

[Japão]
Polifenóis do chá verde (Polyphenon-

E) fornecidos por Mitsui Norin Co., Ltd. (Tóquio, Japão).

Polifenol-E é uma

mistura

epigalocatequina-3$(64,6 \%)$ epigalocatequina

$(4,3 \%)$, epicatequina $(9,4 \%)$, epicatequina3 -galato $(6,4 \%)$

galocatequina-3

galato $(3,5 \%)$,

catequina -3 -galato

$(0,2 \%)$,

galactocatequina

$(0,2 \%)$, catequinas

$(1,1 \%)$ e cafeína

$(0,7 \%)$.
Hamsters sírios machos (8- Grupo $1(\mathrm{n}=10)$ : controle, não 10 semanas com 100-110 g).

DMBA (Sigma Chemical Company, St.

Louis, MO, EUA) a $0.5 \%$ em parafina líquida foi pincelado na bolsa jugal direita dos animais, $3 \mathrm{X} / \mathrm{sem}$ durante 14 semanas. tratados, sem câncer.

Grupo $2(\mathrm{n}=10)$ : controle de droga, administração de $0,05 \%$ de Polifenol-E misturado uma dieta de pellets padrão pré-pesada (Mysore Snack Feed Ltd, Mysore, India),

diariamente, com registro do consumo alimentar.

Grupo $3 \quad(n=10)$ : animais submetidos a indução de câncer, sem tratamento.

Grupo $4 \quad(n=10)$ : animais

submetidos a indução de câncer, receberam $0,05 \%$ de Polifenol-E misturado a uma dieta de pellets padrão prépesada (Mysore Snack Feed Ltd, Mysore, India) diariamente, com registro do
Um aumento significativo na frequência Administração de polifenolde eritrócitos policromáticos micronucleados da medula óssea (MnPCEs) foi encontrado em animais do grupo 3 em comparação com o grupo controle não tratado $(25.5 \pm 2.64, \mathrm{P}<0.01)$. A administração dietética de Polifenol-E para animais DMBA-tratados (grupo 4) diminuiu significativamente a incidência de MnPCEs em comparação com o grupo $3(14.75 \pm 2.5, \mathrm{P}<0,01)$.

Após 14 semanas, a incidência de tumor no grupo 3 foi de $100 \%$, com um número de 1,6 tumores por hamster.

A administração de Polifenol-E diminuiu efetivamente a incidência do tumor $(50 \%$ $\mathrm{P}<0,03)$, o número de tumores $(1.1 \pm$ 1.52) e carga tumoral $(36.73 \pm 81.86$, $\mathrm{P}<0,01$ ), bem como as alterações patológicas.

A administração dietética de Polifenol-E em animais submetidos a indução com
E diminuiu a incidência, a multiplicidade e a carga do tumor, bem como as alterações patológicas. $\mathrm{O}$ polifenol-E funciona como um agente de ação dupla, suprimindo as enzimas da fase I e aumentando as atividades das enzimas da fase II.

Os agentes de dupla ação são reconhecidos por serem mais promissores como agentes quimiopreventivos câncer, pois inibem a ativação metabólica de carcinógenos enquanto promovem a desintoxicação e a excreção. 
Sabitha;

Shyamaladev

i, (2006)

[Índia]

\section{Srinivasan;}

Folhas de chá verde Ratos albinos Wistar machos

frescas coletadas do

distrito de Nilgris

(Índia).

A extração de

polifenóis do chá

verde (GTP 80\%)

seguiu o protocolo

adaptado de Shaowen

Lee (Diretor, Human

King

long

Bioresource Co. Ltd.,

China).

4-NQO (Sigma) a $0,5 \%$ em propilenoglicol pincelado na língua $3 x /$ semana durante 8 semanas.
Dose de polifenóis do chá

Chandra Os polifenóis do chá Hamsters sírios machos (8-

(2006) verde (polifenol-E)

10 semanas com 100-110 g).

ornecidos por Mitsui

[Japão]
Norin Co, Ltd.

(Tóquio, Japão).

7,12-Dimetilbenzantraceno

Polifenol-E é uma (DMBA) a 0,5\% em parafina

mistura de juga

direita

$(0,4 \mathrm{mg})$ epigalocatequina-3- $3 \mathrm{x} /$ semana. consumo alimentar, durante a

indução.

corresponde à ingestão diária

de quatro xícaras de chá (30-

40mg). O experimento fo

encerrado em 14 semanas.

Avaliação do efeito

preventivo.

Grupo $1(n=24)$ : controle, sem

tratamento

$\mathrm{e}$

carcinoma/indução.

rupo $2(n=24)$ : animais foram submetidos a indução por 4-

$\mathrm{NQO} / 8$ sem, na $22^{\mathrm{a}}$ semana

CCE foi desenvolvido, sem tratamento.

Grupo $3 \quad(n=24)$ : grupo controle de drogas - recebeu $200 \mathrm{mg}$ de GTP/kg por gavagem durante 30 dias.

Grupo $4 \quad(n=24)$ : animais submetidos a indução por 4$\mathrm{NQO} / 8$ sem, na $22^{\mathrm{a}}$ semana CCE foi desenvolvido, recebeu $200 \mathrm{mg}$ de GTP/kg por gavagem durante 30 dias, da $22^{\mathrm{a}}$ a $26^{\mathrm{a}}$ semana.

Avaliação

do efeito

terapêutico.

DMBA (Grupo 4) inibiu

significativamente as atividades do

citocromo $\mathrm{P} 450$ e aumentou as atividades das enzimas de fase II na mucosa jugal em comparação com o grupo com câncer sem tratamento (Grupo 3) $(\mathrm{P}<0.05)$.

A administração de polifenol-E elevou todos os antioxidantes na mucosa dos animais dos grupos 2 e 4 em comparação com o grupo 1. tratados, sem câncer.

Grupo $2(\mathrm{n}=10)$ : teste de droga, sem câncer, administração dietética de semanas.

Aumento significativo de
glicoconjugados no grupo de animais com câncer oral quando comparados aos animais controle. Grupo de animais com câncer e tratados com GTP ratos mostraram uma significativa $(\mathrm{p}<0,001)$ diminuição nos glicoconjugados quando comparados com o grupo de animais com câncer sem tratamento. Nenhuma mudança significativa do nível glicoconjugados foi encontrada entre os grupos controle e GTP. Ratos com câncer tratados com GTP mostraram uma ligeira diminuição nos glicoconjugados com degradação de células tumorais. do tumor $(50 \%, \mathrm{p}<0.03)$, a carga do tumor alterações induzidas por

Os resultados sugerem que o

GTP modula tanto a

expressão

glicoconjugados quanto marcadores imunológicos resultando na regressão do câncer oral.

O GTP

atua

munologicamente

modulando

imunocomplexos/níveis

séricos de Ig e atenuando a

ativação de mastócitos, importantes na angiogênese e progressão do câncer oral.

GTP é um candidato potencial na modulação da expressão

glicoconjugados

de marcadores imunológicos para regressão do câncer oral.

Nenhum tumor foi observado nos grupos 1 e 2.

Administração dietética de polifenol-E em 14

semanas

reverteu

significativamente as

$36.73 \pm 81.86 ; \mathrm{p}<0.01)$ e a peroxidação DMBA, através da indução lipídica induzida por DMBA nos de antioxidantes, sugerindo 
galato $\quad(64,6 \%), \quad \mathrm{O}$ experimento foi encerrado

epigalocatequina

$(4,3 \%)$, epicatequina

$(9,4 \%)$, epicatequina-

3-galato $\quad(6,4 \%)$ galocatequina-3-

galato $\quad(3,5 \%)$

catequina -3-galato

$(0,2 \%)$,

galactocatequina

$(0,2 \%)$, catequinas

$(1,1 \%)$ e cafeína

$(0,7 \%)$.

\begin{abstract}
em 14 semanas.
\end{abstract}

\section{Grub} Grupo $3 \quad(n=10): \quad$ teste, submetido a indução de câncer, Grupo $4 \quad(n=10)$ : teste,

Ko et al., Chá verde (Instituto (2007)

[Taiwan]
Nacional de Pesquisa

e Desenvolvimento da

Indústria Alimentar, Taipei, Taiwan)
Hamsters dourados sírios machos (6 semanas).

Benzilnitrosamina - MBN (Ash Stevens, Inc., Detroit, MI, EUA) a $1 \%$ (peso/vol) dissolvido em propilenoglicol foi pincelado 2x/semana durante 17 semanas nas duas bolsas jugais dos animais. sem nenhum tratamento, Grupo $4 \quad(\mathrm{n}=10):$
submetido a indução de câncer e administração dietética de $0,05 \%$ de polifenol-E durante 14 semanas.

A dose de polifenóis do chá verde corresponde à ingestão diária de quatro xícaras de chá (30-40 mg de polifenóis do chá/kg) por humanos).

As dietas experimentais foram preparadas diariamente misturando polifenol-E em uma dieta de pellets padrão pré-pesada (Mysore Snack Feed Ltd., Mysore, Índia), a uma concentração de $0,05 \%$ e o consumo alimentar era registrado.

Avaliação do efeito

preventivo.

eritrócitos $(\mathrm{p}<0.05)$ em comparação com Grupo 3.

A administração dietética de polifenol-E aumentou significativamente todos os antioxidantes (GSH, proporção de GSH/GSSG) e atividades de enzimas dependentes de GSH, nos animais do Grupo 4 em comparação com o Grupo 3 $(\mathrm{p}<0.05)$.

Grupo $1(\mathrm{n}=2)$ : controle, sem câncer, mucosa jugais foram pinceladas

com fornecidos com chá (2).

propilenoglicol (PG) sem A incidência de carcinomas na mucosa MBN 2x/semana durante 17 semanas. (grupo 3) (17,8 $\pm 7,5$ /hamsters) foi significativamente maior do que hamsters tratados com MBN que receberam chá droga, sem câncer, tratados com chá verde a $0,2 \%$ (peso/vol) na água de beber $\begin{array}{lr}\text { (peso/vol) na água de beber } \\ (16,7 \mathrm{ml} / \mathrm{dia}), & \text { trocada }\end{array}$ diariamente, da $9^{\circ}$ à $17^{\mathrm{a}}$ semana, bolsas jugais foram pinceladas

com (grupo 4) $(10,8 \pm 3,9 ; \mathrm{P}<0,05)$

A ingestão de chá foi de aproximadamente $0,03 \mathrm{~g} /$ dia por hamster para os grupos controle (grupo 1) e com fornecimento de chá (grupo 2); e aproximadamente $0,015 \mathrm{~g} / \mathrm{dia}$ por que o chá verde é um agente quimiopreventivo eficaz. 
propilenoglicol (PG) sem MBN, 2x por semana durante 17 semanas.

Grupo $3(\mathrm{n}=6)$ : submetidos a indução de câncer por MBN, ambas as bolsas jugais foram pinceladas com $1 \%$ de $\mathrm{MBN}$ dissolvido em PG 2x/semana durante 17 semanas

Grupo $4(\mathrm{n}=9)$ : submetidos a indução de câncer por MBN por 8 semanas para iniciar a tumorigênese; receberam 0,2\%

de chá verde na água potáve

$(7,6 \mathrm{ml} / \mathrm{dia})$

concomitantemente com a indução do câncer da $9^{\mathrm{a}}$ a $17^{\mathrm{a}}$ semana.

Os animais foram eutanasiados

03 dias após finalizados os experimentos.

Avaliação

do efeito

preventivo.

$\begin{array}{lll}\begin{array}{l}\text { Srinivasan et } \\ \text { al., (2008) }\end{array} & \begin{array}{l}\text { Folhas frescas de chá } \\ \text { verde foram coletadas }\end{array} & \begin{array}{l}\text { Ratos albinos Wistar machos } \\ (80-120 \mathrm{~g}) .\end{array} \\ \begin{array}{l}\text { [República da } \\ \text { do distrito de Nilgris, }\end{array} & \\ & \text { contendo 95,45\% de } & 4-\mathrm{NQO} \quad \text { (Sigma Chemical } \\ & \text { polifenóis (GTP): } & \text { Company, St. Louis, MO) a } \\ & 48,08 \% \text { de EGCG e } & 0,5 \% \text { em propilenoglicol } \\ & 47,36 \% \text { de EGC, após } & \text { pincelado 3x/semana por } 8 \\ & \text { extração. } & \text { semanas na cavidade oral dos } \\ & & \text { animais. }\end{array}$

Grupo $1(\mathrm{n}=8)$ : controle, sem câncer.

Grupo 2 (4-NQO) $\quad(n=15)$ :

submetido a indução de câncer

oral por 4-NQO.

Grupo 3 (GTP) $(n=8)$ : controle

de drogas, sem câncer, recebeu
200mg
$\mathrm{GTP} / \mathrm{kg}$

diariamente da

a $22^{a}$

semana, via oral.

Grupo 4 (4-NQO + GTP

$(n=13): \quad$ tratado, recebeu

simultaneamente $200 \mathrm{mg}$ de

GTP/kg e 4 NQO $0,5 \%$, da $1^{\mathrm{a}}$ a

$10^{\mathrm{a}}$ semana hamster para os grupos tratados com

MBN (grupos 3 e 4).

A incidência de carcinomas foi

significativamente maior em hamsters

tratados com MBN (grupo 3) do que em

animais tratados com MBN/chá (grupo 4)

(17.8 \pm 7.5 vs $10.8 \pm 3.9 ; \mathrm{P}<0,05)$

A expressão da proteína precursora amilóide (APP) também foi significativamente aumentada em carcinomas orais induzidos por MBN mas foi significativamente reduzida pela ingestão de chá $(\mathrm{P}<0,0001)$.
A incidência de tumor de cavidade oral diminuiu em tratamento simultâneo com GTP/indução (grupo 4) em 80\% em relação aos animais induzidos por 4-NQO $(100 \%)$. No grupo póstratamento/indução (grupo 5) houve redução de $70 \%$ em relação aos animais induzidos por 4-NQO (grupo 2) (100\% de câncer).

$\mathrm{O}$ número de tumores da cavidade oral e volume do tumor foram reduzidos significativamente no tratamento simultâneo de GTP (Grupo 4) em 81,77\% e $61,24 \%$, respectivamente em relação aos animais induzidos por 4NQO (grupo 2- $100 \%$ câncer), porém no caso de pós-
GTP inibe as enzimas da Fase I que bioativam o carcinógeno e eleva a atividade das enzimas da Fase II que, por sua vez, aumenta a desintoxicação, eliminando assim o carcinógeno na bile e na urina Assim, constatou-se que o número e o volume do tumor diminuíram. O GTP portanto, modula atividade das enzimas da Fase I e da Fase II e atua como um potencial agente 


\section{Grupo 5 (4-NQO $\rightarrow$ GTP) $(\mathrm{n}=12)$ : grupo \\ 200mg de GTP/kg diariamente \\ da $10^{\mathrm{a}}$ a $22^{\mathrm{a}}$ semana. \\ Os experimentos foram \\ encerrados após 22 semanas. \\ Avaliação dos efeitos preventivos (grupo 4) e \\ terapêuticos (grupo 5)} indução por $4-\mathrm{NQO} \quad 0,5 \%$ e $4 \mathrm{NQO}$ (Grupo 2).

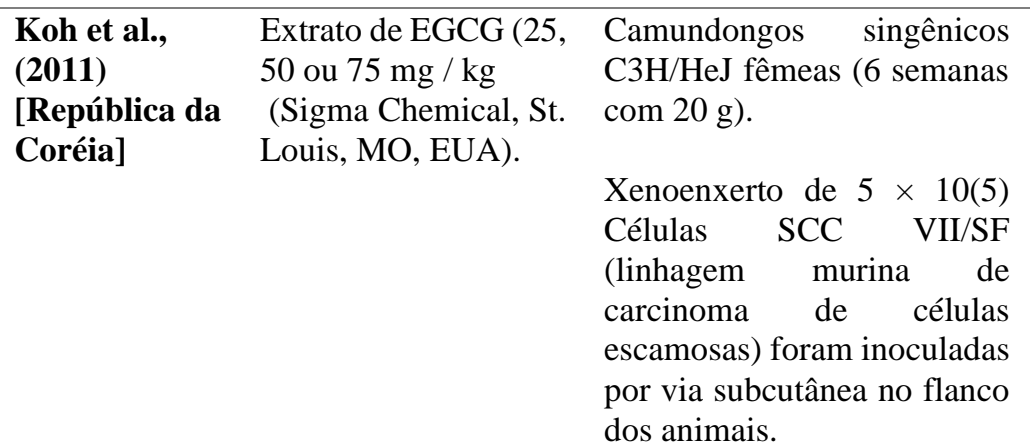

Grupo $1 \quad(n=5)$ : controle animais submetidos a indução, e injeção de diluente seguindo protocolo EGCG.

Grupo $2 \quad(\mathrm{n}=5)$ : animais

submetidos a indução, trat com $25 \mathrm{mg} / \mathrm{kg}$ de EGCG via intraperitoneal diariamente, no dia seguinte a inoculação das células CCE por 22 dias.

Grupo $3 \quad(n=5)$ : animais submetidos a indução, tratados com $50 \mathrm{mg} / \mathrm{kg}$ de EGCG via intraperitoneal diariamente, no dia seguinte a inoculação das células CCE por 22 dias.

Grupo $4 \quad(n=5)$ : animais submetidos a indução, tratados com $75 \mathrm{mg} / \mathrm{kg}$ de EGCG via intraperitoneal diariamente, no dia seguinte a inoculação das células CCE por 22 dias.

Avaliação do efeito terapêutico tratamento (grupo 5) de GTP a redução quimiopreventivo

terapêutico

E crescimento tumoral e a invasão da linhagem de células de câncer oral por meio da supressão da via de sinalização

HGF/c-Met. EGCG induziu uma forte

redução na fosforilação de c-Met e expressão de HGF, ao se compara grupo tratado com $25 \mathrm{mg} / \mathrm{kg}$ e controle.

$\mathrm{O}$ crescimento do tumor foi suprimido e a apoptose foi aumentada por EGCG.

A administração de EGCG afetou significativamente o crescimento do tumor vs. controle, e as diferenças observadas no desenvolvimento do tumor no grupo EGCG $50 \mathrm{mg} / \mathrm{kg}$ em comparação com o grupo EGCG 25 $\mathrm{mg} / \mathrm{kg}$ foram significativas. Assim, EGCG pareceu produzir inibição do crescimento tumoral dependente da dose in vivo. No entanto, a administração de 75 $\mathrm{mg} / \mathrm{kg}$ de EGCG resultou em ingestão oral pobre, perda de peso e letargia, e quatro camundongos morreram em 3 semanas.

Com o aumento da dose de EGCG, de 25 para $75 \mathrm{mg} / \mathrm{kg}$, o número de células positivas para caspase- 3 tendeu a aumentar de maneira dependente da dose.
O EGCG pode ser um potencial agente terapêutico para inibir o crescimento tumoral induzido por HGF e reduzir a invasão de células

do câncer oral. 


\begin{tabular}{ll}
\hline Hwang; & EGCG \\
Park; Chung, & epigalocatequina-3 \\
(2013) & galato (Sigma \\
[República da & Chemical Co., St St \\
Coréia] & Louis, MO, EUA)
\end{tabular}

\section{Camundongos}

atímicos Balb/C nudes semanas).

Coréia]

Louis, MO, EUA)
Xenoenxerto de células da linhagem de carcinoma de células escamosas oral

(CCEO) YD-10B, Grupo $2(n=5)$ : animais com solubilizadas em DMSO a xenoenxerto, tratados com 20 $0,1 \%$ (5 x10(5) céls $/ 0,1 \quad \mathrm{mg}$ de EGCG $/ 0,1 \%$ DMSO $/ \mathrm{kg}$, $\mathrm{ml} /$ animal), inoculado na via intraperitoneal, 2 dias após submucosa da língua dos a inoculação das céls animais, e esperado o cancerosas, em dias alternados, desenvolvimento do tumor. por 4 semanas.

Avaliação do terapêutico.
Já o número de células positivas para PCNA diminuiu conforme a dose de EGCG aumentou.

A administração de EGCG levou à inibição substancial do crescimento tumoral e ativação de proteínas de invadopódios nos tecidos tumorais de camundongos inoculados com células CCEO.

$\mathrm{O}$ volume do tumor aumentou ao longo das 4 semanas em camundongos inoculados com células YD-10B OSCC e tratado com DMSO (diluente), mas as injeções intraperitoneais de EGCG inibiram significativamente o volume tumoral.

Os tumores inoculados na língua eram CCE bem diferenciados e altamente invasivos, enquanto os de camundongos suplementados com EGCG eram encapsulados. A expressão das proteínas Src, CTTN e FAK foi significativamente inibida pelo tratamento com EGCG. A expressão de MT1-MMP, MMP-9 e MMP-2 foi inibida pelo tratamento com EGCG.

O EGCG inibiu a invasão do câncer ao impedir a formação de invadopódios funcionais principalmente por meio da ativação de Src, CTTN, FAK e RhoA em células humanas OSCC YD-10B.

\begin{tabular}{|c|c|c|c|c|c|}
\hline $\begin{array}{l}\text { Yoshimura et } \\
\text { al., (2019) } \\
\text { [Japão] }\end{array}$ & $\begin{array}{l}\text { Epigalocatequina-3 } \\
\text { galato } \\
\text { (EGCG) (Sigma). }\end{array}$ & $\begin{array}{l}\text { Camundongos BALB/c nude } \\
\text { fêmeas ( } 5 \text { semanas com } 20 \text { - } \\
25 \mathrm{~g}) \text {. } \\
\text { Xenoenxerto de } 5 \quad \times \\
10^{6} \text { células HSC-3 (CCE } \\
\text { humano de língua) em } 50 \mu 1 \\
\text { de } \alpha \text {-MEM suplementado }\end{array}$ & $\begin{array}{l}\text { Duas semanas após o } \\
\text { xenoenxerto: } \\
\text { Grupo 1 } \quad(\mathrm{n}=10) \text { : controle, } \\
\text { animais com xenoenxerto, } \\
\text { injeção de solução salina via } \\
\text { intraperitoneal, 2x/semana } \\
\text { durante } 4 \text { semanas. }\end{array}$ & $\begin{array}{l}\text { Uma diferença significativa foi observada } \\
\text { a partir de } 1 \text { semana após a administração } \\
\text { de EGCG, entre os grupos. No grupo } \\
\text { EGCG houve redução de } 45,2 \% \text { no } \\
\text { volume do tumor em comparação com os } \\
\text { animais controle }(46,7 \pm 17,8 \text { vs } 103,4 \pm \\
\left.12,4 \mathrm{~mm}^{3}\right) \text {. O peso dos camundongos não }\end{array}$ & $\begin{array}{l}\text { A inibição significativa do } \\
\text { crescimento do carcinoma de } \\
\text { células escamosas oral em } \\
\text { camundongos tratados com } \\
\text { EGCG, sem perda de peso } \\
\text { corporal, sugere que o EGCG } \\
\text { é um potencial agente } \\
\text { anticâncer para tratamento do }\end{array}$ \\
\hline
\end{tabular}

A administração de EGCG suprimiu o crescimento do tumor e a infiltração regional no estroma circundante. As descobertas mostram claramente que EGCG é um agente quimiopreventivo dietético eficaz ao diminuir a formação de invadopódios funcionais no câncer oral. EGCG é um agente antiinvasivo promissor ao inibir a formação de invadopódios, com potencial para aplicação na terapia contra o câncer. anticancer para tratamento do 
Research, Society and Development, v. 10, n. 8, e1510817039, 2021

(CC BY 4.0) | ISSN 2525-3409 | DOI: http://dx.doi.org/10.33448/rsd-v10i8.17039

com $10 \%$ de SFB foram Grupo $2(\mathrm{n}=10)$ : teste, animais misturados com $50 \mu \mathrm{l}$ de Matrigel (BD Biosciences) e implantados

subcutaneamente no dorso dos animais. com xenoenxerto, $75 \mathrm{mg} / \mathrm{kg}$ de

EGCG foram injetados via intraperitoneal, $2 \mathrm{x} / \mathrm{seman}$

urante 4 semanas.

Avaliação

terapêutico. diminuiu/diferiu significativamente nos

grupos.

Houve diferenças significativas na

expressão média de $\mathrm{Ki}-67$ entre o grupo

teste e o grupo de controle $(8,8$

$5,0 \pm 2,4 \%$ )

A porcentagem de células apoptóticas no

grupo teste foi significativamente maior

do que no grupo de controle $(10,6 \pm 4,2$ a

$4,4 \pm 2,3 \%)$ carcinoma

células escamosas oral.

Fonte: Autores (2021). 
Research, Society and Development, v. 10, n. 8, e1510817039, 2021

(CC BY 4.0) | ISSN 2525-3409 | DOI: http://dx.doi.org/10.33448/rsd-v10i8.17039

As principais características dos artigos científicos incluídos foram relacionadas na Tabela 02. Dentre as publicações, os anos de maior prevalência de estudos sobre o tema em questão foram na primeira década dos anos 2000, com 7 trabalhos (63.63\%), seguido da segunda década, com 3 estudos (27.27\%) e 1 estudo de 1999 (9,1\%). Dos 11 artigos, 10 (90,9\%) são estudos realizados por países orientais. Além disso, pode-se observar também uma variedade de formas de obtenção do chá para o estudo do efeito no carcinoma de células escamosas, seja no formato da folha fresca, em pó comercial, extrato ou compostos isolados como a epigalocatequina-3-galato (EGCG).

Dentre as formas utilizadas nos estudos incluídos nessa revisão, incluem-se: polifenol-E em 2 (18,1\%), chá verde em 3 (27,3\%), polifenóis totais do chá verde (GTP) em 3 (27,3\%) e os estudos mais recentes (3) utilizaram a EGCG isolada (27,3\%). O tempo de tratamento dos animais com essas substâncias variou de 3 a 18 semanas e não houve uma dose padrão de utilização do chá verde/compostos, visto que a forma de administração variou muito dentre os estudos incluídos. A concentração da EGCG (forma isolada) variou de $15,1 \%$ a $64,6 \%$, sendo esta última a mais utilizada. Já a dose de EGCG variou de 20 a $75 \mathrm{mg} / \mathrm{kg}$ e a dose mais utilizada foi de $75 \mathrm{mg} / \mathrm{kg}$. A dose de GTP isolado foi de $200 \mathrm{mg} / \mathrm{kg}$, em concentrações de 80\% a 95,45\%. Já o PolifenolE foi administrado a uma concentração de 0,05\%, com dose de 30-40 mg/kg. O chá verde foi administrado em concentrações que variaram de $0,2 \%$ a $1,5 \%$, em doses de até $6 \mathrm{mg} / \mathrm{ml}$ e $16 \mathrm{ml} /$ dia na água de beber.

No que se refere aos modelos animais utilizados, notou-se uma maior utilização dos hamsters, em 5 estudos (45,45\%), seguido dos ratos e camundongos, ambos com 3 estudos (27,27\%). Houve o monitoramento do peso corporal dos animais em apenas dois estudos $(18,1 \%)$. Os carcinógenos mais utilizados foram o DMBA com 4 estudos (36,36\%) seguido do 4NQO e das células de carcinoma em xenoenxerto, ambos com 3 estudos (27,27\%), além de MBN com 1 estudo (9,1\%).

Dentre os 11 estudos incluídos, 6 (54,54\%) abordaram os efeitos terapêuticos do chá verde no carcinoma de células escamosas oral, $4(36,36 \%)$ discutiram seus efeitos preventivos e $1(9,1 \%)$ avaliou ambos os efeitos. Nesses trabalhos, observouse redução na incidência, número, volume e crescimento e tumores em animais tratados com o chá verde, EGCG, GTP e polifenol-E, através de diversos mecanismos de ação (estresse oxidativo, apoptose, inibição da proliferação e diferenciação celular) e efeitos moleculares (alteração na expressão de glicoconjugados, proteínas precursoras amilóides, metaloproteinases e na formação de invadopódios), evidenciando as atividades quimiopreventivas e anticarcinogênicas dessas preparações.

\section{Discussão}

O câncer oral é um tumor maligno que pode afetar lábios e estruturas da boca, como gengivas, mucosa jugal, palato, língua e assoalho, com alta taxa de morbimortalidade e comprometendo a qualidade de vida, principalmente devido a ocorrência de deformidades faciais resultantes do tratamento (Montero; Patel, 2015; Tandon et al., 2017). Por isso, o tratamento do câncer de boca ainda permanece como um desafio devido a sua complexidade, motivando a busca por tratamentos mais eficientes ou tratamentos adjuvantes (Rivera, 2015).

A carcinogênese pode ocorrer por ação de uma série de fatores distintos, sejam estes químicos (hidrocarbonetos policíclicos aromáticos), físicos (raio ultravioleta, radiação ionizante) ou biológicos (vírus, a exemplo do HPV) (Telles, 1999). Os principais exemplos de carcinógenos químicos são o DMBA (9,10-dimetil 1,2-benzantraceno ou 7,12-dimetilbenzantraceno), o metilcolantreno, o benzopireno e o 4-quinolina 1-óxido (4NQO), sendo este último o carcinógeno químico mais utilizado para a indução do câncer oral, devido à natureza diversa e heterogênea das lesões resultantes e à facilidade de observar suas características, assemelhando-se ao processo natural de desenvolvimento das lesões nos seres humanos (Kanojia; Vaidya, 2006). Em geral, os modelos induzidos por carcinógenos não permitem o estudo de genes específicos no processo de carcinogênese oral, sendo utilizado o xenoenxerto para este propósito (Ishida et al., 2017). 
Research, Society and Development, v. 10, n. 8, e1510817039, 2021

(CC BY 4.0) | ISSN 2525-3409 | DOI: http://dx.doi.org/10.33448/rsd-v10i8.17039

O uso de modelos animais ainda é crucial para o estudo do câncer oral. Em nossa revisão foram identificados estudos em hamsters, camundongos e ratos. As vantagens e desvantagens da utilização de cada modelo deve ser avaliada de forma criteriosa tendo em vista que, até o presente momento, não há modelo ideal semelhante ao carcinoma de células escamosas em humanos (Ishida et al., 2017). Este seria uma combinação de um modelo induzido por carcinógeno e um modelo transgênico, no qual a aplicação de agentes carcinogênicos a camundongos transgênicos levaria à formação inicial de tumor, sendo análogo à exposição crônica ao tabaco e álcool em um indivíduo com predisposições genéticas ou epigenéticas para desenvolver câncer na cavidade oral (Ishida et al., 2017).

Modelos de estudo com camundongos quimicamente induzidos ao câncer, modelos de camundongos geneticamente modificados e modelos transplantados (xenoenxertos) são amplamente utilizados. O tamanho dos animais, a criação em cativeiro, a expectativa de vida e principalmente as semelhanças fisiológicas e moleculares com os humanos e o sequenciamento completo do genoma são questões que devem ser consideradas ao escolher o modelo a ser utilizado (Ishida et al., 2017).

Apenas dois estudos realizaram o monitoramento do peso corporal dos animais nas pesquisas O parâmetro peso corporal no estudo em modelo animal é importante ser monitorado pois a perda de peso é uma característica importante dessa patologia e as lesões em boca podem levar ao desenvolvimento de disfagia. Ainda, o comprometimento alimentar pode apresentar sério agravo à vida, além de comprometer a administração por via oral do chá. Em sua pesquisa, Koh et al., (2011) observaram que ao ser administrada uma dose de 75mg do extrato EGCG houve perda de peso e letargia nos animais, porém Yoshimura et al., (2019), após administração de 75 mg de EGCG, não reportaram perda de peso corporal, ressaltando o seu potencial como agente anticâncer.

O chá verde, derivado da planta medicinal Camellia sinensis, por ser biocompatível e ter ação antioxidante, vem sendo explorado como possível droga para tratamento do câncer, sendo atestada a inibição da proliferação de células cancerosas (Filippini et al., 2020; Liao et al., 2020). O maior quantitativo de estudos em países orientais pode ser justificado pelo maior hábito de consumo de chá nestes países visto que os hábitos pessoais variam culturalmente (Filippini et al., 2020).

Ainda, um estudo de revisão de atualização do Banco de Dados de Revisões Sistemáticas da Cochrane avaliou 5 estudos relacionando o chá verde e o câncer oral em humanos, com um número total de 55.977 participantes e concluiu existir um grande efeito, porém com risco alto de viés devido a estudos caso-controle (Filippini et al., 2020). Logo, é importante fortalecer as evidências com estudos pré-clínicos com objetivo de estabelecer e explicar o mecanismo dinâmico de ação do chá verde no carcinoma de células escamosas oral, antes da realização de estudos de maior confiabilidade cientifica como ensaios clínicos randomizados.

O chá verde contém vários componentes polifenóis que são antioxidantes por natureza e estudos mostraram que este é capaz de prevenir danos celulares induzidos por oxidantes (Katiyar; Mukhtar, 1996). Os polifenóis do chá verde (GTPs) são as catequinas e epicatequinas como a epigalocatequina-3-galato (EGCG), epigalocatequina (EGC), epicatequina-3-galato (ECG) e epicatequina (EC) (Srinivasan; Sabitha; Shyamaladevi, 2004). O estudo de Srinivasan et al. (2008) constatou a ação quimiopreventiva e terapêutica dos polifenóis totais do chá verde (48,08\% de EGCG e 47,36\% de ECG) pela diminuição do número e volume dos tumores da cavidade oral. Além disso, Li et al. (2002) reportaram que, a administração do chá verde inibiu a carcinogênese oral na fase pós-iniciação, a partir do aumento significativo do grau de apoptose, tanto nas displasias quanto no CCEO, além da redução da proliferação celular.

Dentre os componentes do chá verde, destacam-se as catequinas, sendo a EGCG a mais estudada atualmente. Diversos estudos avaliaram os efeitos da EGCG em vários alvos moleculares, tanto in vitro quanto em modelos in vivo, na quimioprevenção e no tratamento do câncer (Nagle; Ferreira; Zhou, 2006; Somers-Edgar et al., 2007; Wang; Weber; Henning, 
Research, Society and Development, v. 10, n. 8, e1510817039, 2021

(CC BY 4.0) | ISSN 2525-3409 | DOI: http://dx.doi.org/10.33448/rsd-v10i8.17039

2012; Relat et al., 2012; Jang et al., 2013; Rady et al., 2018). A EGCG tem demonstrado potencial de induzir a parada do ciclo celular e a apoptose em células de CCEO humanas, resultando em efeitos antiproliferativos (Yoshimura et al., 2019).

Tanto os efeitos quimiopreventivos quanto os terapêuticos do chá verde no combate ao câncer oral devem ser explorados, visto que é um produto natural de baixo custo, com quase nenhum efeito adverso. Os efeitos terapêuticos das catequinas do chá verde no câncer incluem a inibição do estresse oxidativo, indução da apoptose, inibição da angiogênese e inibição de metástases em vários estágios da tumorigênese por meio da modulação de vias de sinalização, de atividade enzimática e de proteínas quinases (Cheng et al., 2020). Já a quimioprevenção é o uso de produtos naturais ou químicos sintéticos para a reversão, supressão ou prevenção da transformação de células pré-malignas para a forma maligna (Lee; Choi, 2011). A atividade preventiva dos constituintes do chá no câncer já foi demonstrada em muitos estudos in vitro e em modelos animais, incluindo câncer de pele, pulmão, cavidade oral, esôfago, estômago, fígado, pâncreas, intestino delgado, cólon, bexiga, próstata e glândula mamária (Yang et al., 2008).

Considerando-se a variedade de compostos fenólicos do chá verde, o estresse oxidativo constitui-se como seu principal alvo, ao se abordar a carcinogênese. Estimulado por fatores endógenos e exógenos, as espécies reativas de oxigênio (ERO) induzem danos celulares. Alguns mecanismos de defesa compreendem os antioxidantes endógenos, como a superóxido dismutase, glutationa peroxidizada e catalase, que podem compensar os microambientes oxidativos. Antioxidantes exógenos não enzimáticos, como vitaminas, minerais e polifenóis, também têm a capacidade de extinguir a atividade de ERO ao reagir com radicais livres oxidantes, por exemplo, evitando danos celulares e a transformação maligna (Ziech et al., 2010; Yasueda; urushima; Ito, 2015).

Os efeitos anticarcinogênicos do chá verde ocorrem através de diversos mecanismos. Li, Han e Chen (1999) constataram uma redução na frequência de células micronucleadas, no número/volume de AgNOR (regiões organizadoras de nucléolos coradas por prata, relacionadas à proliferação celular), na quantidade de PCNA (antígeno nuclear de proliferação celular, reflete o estado de ativação celular) e no nível de expressão do receptor do fator de crescimento epidérmico (EGF, glicoproteína que regula o crescimento celular, sua expressão amplificada está relacionada a certas neoplasias epiteliais) nas células da mucosa oral, resultando na diminuição do número, volume e carga de tumores após administração de preparações do chá verde. No estudo de Srinivasan, Sabitha e Shyamaladevi., (2006) os resultados sugerem que os polifenóis totais do chá verde (GTP) reduzem a expressão de glicoconjugados (compostos essenciais na formação de glicoproteínas, que são moléculas capazes de provocar transformações neoplásicas) e modula marcadores imunológicos (imunoglobulinas séricas, mastócitos e complexos imunes circulantes - CIC), resultando na regressão do câncer oral.

Os efeitos quimiopreventivos e terapêuticos do polifenol-E e do GTP foram relatados por Chandra Mohan et al. (2005) e Srinivasan et al. (2008), respectivamente, através da inibição das enzimas da Fase I, que bioativam o carcinógeno e na elevação das enzimas da Fase II, que desempenham um papel desintoxicante. Ko et al. (2007) verificaram o efeito quimiopreventivo do chá verde na redução da expressão e secreção da proteína precursora amiloide (APP), que desempenha um papel importante na proliferação e diferenciação celular, sendo considerada um regulador positivo da carcinogênese, por células de CCEO. Outro mecanismo relatado nos estudos é o aumento dos níveis de antioxidantes (GSH, proporção de GSH/GSSG) resultante da administração de chá verde na inibição do desenvolvimento do câncer (Srinivasan; Sabitha; Shyamaladevi, 2004; Chandra Mohan et al., 2005; Chandra Mohan et al., 2006)

Koh et al. (2011) verificaram que a EGCG inibiu significativamente o crescimento tumoral e a invasão da linhagem de células de carcinoma de células escamosas oral por meio da supressão da via HGF/c-Met (fator de crescimento de hepatócitos/proteína c-Met), cuja superexpressão resulta na ativação de várias vias de sinalização, contribuindo para a invasão 
Research, Society and Development, v. 10, n. 8, e1510817039, 2021

(CC BY 4.0) | ISSN 2525-3409 | DOI: http://dx.doi.org/10.33448/rsd-v10i8.17039

celular e metástase, além da inibição da ativação das enzimas metaloproteinases da matriz (MMP-2 e MMP-9, que também desempenham importantes papeis na invasão tumoral e metástases, além de aumentar a apoptose. Concluíram que a EGCG pode ser um potencial agente terapêutico no câncer oral.

Hwang, Park e Chung (2013) observaram que a administração de EGCG reduziu o crescimento tumoral e a infiltração regional no estroma circundante, além da inibição da formação de invadopódios, importantes mediadores da invasão local durante a metástase, principalmente por meio da diminuição da fosforilação de Src (estimula a formação de invadopódios em fibroblastos e células de carcinomas), de CTTN (importante proteína para formação de invadopódios, relacionada à motilidade das células tumorais) e de FAK (a sinalização FAK/Src leva à remodelação do citoesqueleto para invasão e migração de células), além de redução da ativação de Rhoa (localizada nos invadopódios, essencial para a formação, regulação e potencial invasivo de fibroblastos transformados por Src). Além disso, o EGCG inibe a expressão do MT1-MMP, MMP-9 e MMP-2 (metaloproteinanses da matriz, relacionadas à maturação dos invadopódios), exibindo potencial na terapia do câncer oral (Hwang; Park; Chung, 2013). Por fim, constata-se que os mecanismos antitumorais do chá verde frente ao carcinoma de células escamosas oral são diversos e complexos. Mais pesquisas clínicas e moleculares são necessárias para elucidar a atividade do chá verde e seus compostos na terapia do câncer oral.

\section{Considerações Finais}

Diante do exposto, conclui-se que o chá verde possui efeito antitumoral no carcinoma de células escamosas oral, exercendo ação tanto quimiopreventiva quanto terapêutica, por diferentes vias. Merece destaque a ação antioxidante dos polifenóis da Camellia Sinensis, ao reduzir a proliferação das células cancerosas. A EGCG constitui-se como o composto do chá verde mais explorado, sendo considerada uma droga promissora para a prevenção e terapia do câncer.

Ainda, estudos acerca da aplicação do chá verde no tratamento/prevenção do carcinoma de células escamosas oral se mostram importantes, tendo em vista suas ações antiproliferativas já conhecidas e por ser um produto natural, biocompatível, seguro e de fácil acesso/baixo custo. O conhecimento do seu mecanismo de ação pode contribuir para estabelecer e delinear novas estratégias de intervenção no combate ao carcinoma de células escamosas oral, o tipo mais frequente de câncer de boca, melhorando o prognóstico dos indivíduos acometidos com essa patologia. Maiores estudos, in vitro, pré-clinicos e clinicos tornam-se necessários para avaliação mais acurada dos vários mecanismos de ação do chá verde no carcinoma de células escamosas oral.

\section{Referências}

Chandra Mohan, K. V. P., Hara, Y., Abraham, S. K., \& Nagini, S. (2005). Comparative evaluation of the chemopreventive efficacy of green and black tea polyphenols in the hamster buccal pouch carcinogenesis model. Clinical biochemistry, 38(10), 879-886.

Chandra Mohan, K. V. P., Subapriya, R., Hara, Y., \& Nagini, S. (2006). Enhancement of erythrocyte antioxidants by green and black tea polyphenols during 7,12-dimethylbenz[a]anthracene-induced hamster buccal pouch carcinogenesis. Journal of medicinal food, 9(3), 373-377.

Cheng, Z., Zhang, Z., Han, Y., Wang, J., Wang, Y., Chen, X., Shao, Y., Cheng, Y., Zhou, W., Lu, X., \& Wu, Z. (2020). A review on anti-cancer effect of green tea catechins. Journal of Functional Foods, 74, 104-172.

Chimenos-Küstner, E., Marques-Soares, M. S., \& Schemel-Suárez, M. (2019). Consideraciones sobre etiopatogenia y prevención del cáncer orofaríngeo [Aetiopathology and prevention of oropharyngeal cancer]. Semergen, 45(7), 497-503.

Chowdhury, A., Sarkar, J., Chakraborti, T., Pramanik, P. K., \& Chakraborti, S. (2016). Protective role of epigallocatechin-3-gallate in health and disease: A perspective. Biomedicine \& pharmacotherapy = Biomedecine \& pharmacotherapie, 78, 50-59.

Filippini, T., Malavolti, M., Borrelli, F., Izzo, A. A., Fairweather-Tait, S. J., Horneber, M., \& Vinceti, M. (2020). Green tea (Camellia sinensis) for the prevention of cancer. The Cochrane database of systematic reviews, 3(3), CD005004. 
Research, Society and Development, v. 10, n. 8, e1510817039, 2021

(CC BY 4.0) | ISSN 2525-3409 | DOI: http://dx.doi.org/10.33448/rsd-v10i8.17039

Herrera-Serna, B. Y., Lara-Carrillo, E., Toral-Rizo, V. H. Amaral, R. C. (2019). Efecto de las políticas de control de factores de riesgo sobre la mortalidad por cáncer oral en América Latina. Revista espanola de salud publica, 93, e201907050.

Hwang, Y. S., Park, K. K., \& Chung, W. Y. (2013). Epigallocatechin-3 gallate inhibits cancer invasion by repressing functional invadopodia formation in oral squamous cell carcinoma. European journal of pharmacology, 715(1-3), 286-295.

INCA. (2021). Câncer de boca. https://www.inca.gov.br/tipos-de-cancer/cancer-de-boca

Ishida, K., Tomita, H., Nakashima, T., Hirata, A., Tanaka, T., Shibata, T., \& Hara, A. (2017). Current mouse models of oral squamous cell carcinoma: Genetic and chemically induced models. Oral oncology, 73, 16-20.

Jang, J. Y., Lee, J. K., Jeon, Y. K., \& Kim, C. W. (2013). Exosome derived from epigallocatechin gallate treated breast cancer cells suppresses tumor growth by inhibiting tumor-associated macrophage infiltration and M2 polarization. BMC cancer, 13, 421.

Kanojia, D., \& Vaidya, M. M. (2006). 4-nitroquinoline-1-oxide induced experimental oral carcinogenesis. Oral oncology, 42(7), 655-667.

Katiyar, S., \& Mukhtar, H. (1996). Tea in chemoprevention of cancer. International journal of oncology, 8(2), 221-238.

Ko, S. Y., Chang, K. W., Lin, S. C., Hsu, H. C., \& Liu, T. Y. (2007). The repressive effect of green tea ingredients on amyloid precursor protein (APP) expression in oral carcinoma cells in vitro and in vivo. Cancer letters, 245(1-2), 81-89.

Koh, Y. W., Choi, E. C., Kang, S. U., Hwang, H. S., Lee, M. H., Pyun, J., Park, R., Lee, Y., \& Kim, C. H. (2011). Green tea (-)-epigallocatechin-3-gallate inhibits HGF-induced progression in oral cavity cancer through suppression of HGF/c-Met. The Journal of nutritional biochemistry, 22(11), 1074-1083.

Lee, U. L., \& Choi, S. W. (2011). The chemopreventive properties and therapeutic modulation of green tea polyphenols in oral squamous cell carcinoma. ISRN oncology, 2011, 403707.

Li, N., Chen, X., Liao, J., Yang, G., Wang, S., Josephson, Y., Han, C., Chen, J., Huang, M. T., \& Yang, C. S. (2002). Inhibition of 7, 12dimethylbenz[a]anthracene (DMBA)-induced oral carcinogenesis in hamsters by tea and curcumin. Carcinogenesis, 23(8), 1307-1313.

Li, N., Han, C., \& Chen, J. (1999). Tea preparations protect against DMBA-induced oral carcinogenesis in hamsters. Nutrition and cancer, 35(1), 73-79.

Liao, S., Tang, Y., Chu, C., Lu, W., Baligen, B., Man, Y., \& Qu, Y. (2020). Application of green tea extracts epigallocatechin-3-gallate in dental materials: Recent progress and perspectives. Journal of biomedical materials research. Part A, 108(12), 2395-2408.

Maciel, J. A. C., Castro-Silva, I. I. (2021). Mortalidade por câncer de boca frente às desigualdades sociais e o desenvolvimento humano no brasil: um estudo ecológico. Hygeia - Revista Brasileira de Geografia Médica e Da Saúde, 17, 45-54.

Maggioni, D., Biffi, L., Nicolini, G., \& Garavello, W. (2015). Flavonoids in oral cancer prevention and therapy. European journal of cancer prevention: the official journal of the European Cancer Prevention Organisation (ECP), 24(6), 517-528.

Moghadamtousi, S. Z., Fadaeinasab, M., Nikzad, S., Mohan, G., Ali, H. M., \& Kadir, H. A. (2015). Annona muricata (Annonaceae): A Review of Its Traditional Uses, Isolated Acetogenins and Biological Activities. International journal of molecular sciences, 16(7), 15625-15658.

Montero, P. H., \& Patel, S. G. (2015). Cancer of the oral cavity. Surgical oncology clinics of North America, 24(3), 491-508.

Nagle, D. G., Ferreira, D., \& Zhou, Y. D. (2006). Epigallocatechin-3-gallate (EGCG): chemical and biomedical perspectives. Phytochemistry, 67(17), 18491855 .

Peter, B., Bosze, S., \& Horvath, R. (2017). Biophysical characteristics of proteins and living cells exposed to the green tea polyphenol epigallocatechin-3-gallate (EGCg): review of recent advances from molecular mechanisms to nanomedicine and clinical trials. European biophysics journal: EBJ, 46(1), 1-24.

Rady, I., Mohamed, H., Rady, M., Siddiqui, I. A., Mukhtar, H. (2018). Cancer preventive and therapeutic effects of EGCG, the major polyphenol in green tea. Egyptian Journal Of Basic And Applied Sciences, 5(1), 1-23.

Relat, J., Blancafort, A., Oliveras, G., Cufí, S., Haro, D., Marrero, P. F., \& Puig, T. (2012). Different fatty acid metabolism effects of (-)-Epigallocatechin-3Gallate and $\mathrm{C} 75$ in Adenocarcinoma lung cancer. BMC Cancer, 12(1).

Rivera C. (2015). Essentials of oral cancer. International journal of clinical and experimental pathology, 8(9), 11884-11894.

Somers-Edgar, T. J., Scandlyn, M. J., Stuart, E. C., Le Nedelec, M. J., Valentine, S. P., \& Rosengren, R. J. (2007). The combination of epigallocatechin gallate and curcumin suppresses ER $\alpha$-breast cancer cell growth in vitro and in vivo. International Journal of Cancer, 122(9), 1966-1971.

Srinivasan, P., Sabitha, K. E., Shyamaladevi, C. S. (2004). Therapeutic efficacy of green tea polyphenols on cellular thiols in 4-Nitroquinoline 1-oxide-induced oral carcinogenesis. Chemico-biological interactions, 149(2-3), 81-87.

Srinivasan, P., Sabitha, K. E., Shyamaladevi, C. S. (2006). Modulatory efficacy of green tea polyphenols on glycoconjugates and immunological markers in $4-$ Nitroquinoline 1-oxide-induced oral carcinogenesis-A therapeutic approach. Chemico-biological interactions, 162(2), 149-156.

Srinivasan, P., Suchalatha, S., Babu, P. V., Devi, R. S., Narayan, S., Sabitha, K. E., \& Shyamala Devi, C. S. (2008). Chemopreventive and therapeutic modulation of green tea polyphenols on drug metabolizing enzymes in 4-Nitroquinoline 1-oxide induced oral cancer. Chemico-biological interactions, 172(3), $224-234$. 
Research, Society and Development, v. 10, n. 8, e1510817039, 2021

(CC BY 4.0) | ISSN 2525-3409 | DOI: http://dx.doi.org/10.33448/rsd-v10i8.17039

Tandon, P., Dadhich, A., Saluja, H., Bawane, S., \& Sachdeva, S. (2017). The prevalence of squamous cell carcinoma in different sites of oral cavity at our Rural Health Care Centre in Loni, Maharashtra - a retrospective 10-year study. Contemporary oncology (Poznan, Poland), 21(2), 178-183.

Telles, O. S. (1996). Carcinogênese biomolecular em cancerologia. J Biomolec med Free Rad., 5 (2), 49-52.

Torres-Pereira, C. C., Angelim-Dias, A. Melo, N. S., Junior, C. A. L., Oliveira, E. M. F. (2012) Abordagem do câncer da boca: uma estratégia para os níveis primário e secundário de atenção em saúde. Cadernos de Saúde Pública, 28, 30-39.

Wang, P., Heber, D., \& Henning, S. M. (2012). Quercetin increased the antiproliferative activity of green tea polyphenol (-)-epigallocatechin gallate in prostate cancer cells. Nutrition and cancer, 64(4), 580-587.

Yang, C. S., Ju, J., Lu, G., Xiao, H., Hao, X., Sang, S., \& Lambert, J. D. (2008). Cancer prevention by tea and tea polyphenols. Asia Pacific journal of clinical nutrition, 17 Suppl 1(Suppl 1), 245-248.

Yasueda, A., Urushima, H., \& Ito, T. (2016). Efficacy and Interaction of Antioxidant Supplements as Adjuvant Therapy in Cancer Treatment: A Systematic Review. Integrative cancer therapies, 15(1), 17-39.

Yoshimura, H., Yoshida, H., Matsuda, S., Ryoke, T., Ohta, K., Ohmori, M., Yamamoto, S., Kiyoshima, T., Kobayashi, M., \& Sano, K. (2019). The therapeutic potential of epigallocatechin 3 gallate against human oral squamous cell carcinoma through inhibition of cell proliferation and induction of apoptosis: In vitro and in vivo murine xenograft study. Molecular medicine reports, 20(2), 1139-1148.

Ziech, D., Franco, R., Georgakilas, A. G., Georgakila, S., Malamou-Mitsi, V., Schoneveld, O., Pappa, A., \& Panayiotidis, M. I. (2010). The role of reactive oxygen species and oxidative stress in environmental carcinogenesis and biomarker development. Chemico-biological interactions, 188(2), 334-339. 